\title{
METODE PEMBELAJARAN MONTESSORI BERBASIS ALAT PERAGA MATEMATIKA BERBAHAN LIMBAH KARET SPONS TERHADAP PARTISIPASI AKTIF SISWA
}

\author{
Susilawati $^{1}$, Widia Nur Jannah ${ }^{2}$ \\ Fakultas Keguruan dan Ilmu Pendidikan Universitas Muhammadiyah Cirebon
}

\begin{abstract}
This study aims to determine the effect of mathematic props based montessori learning methods made from rubber sponge waste through active participation of 5 th grade students. This study uses an experimental method (Pretest-Posttes Control Group Desaign) by using observation sheets, questionnaires and students' worksheets. The influence is analyzed using n-gain and t-test. The subjects of this study are 5th grade students of Klangenan Subdistrict. The results of this study indicate that mathematics teaching aids based montessory learning method made from sponge rubber waste affects the active participation of 5th grade students. It can be seen from the average value of the experimental class students' posttest has increased by 28.70. There is a difference in the mean posttest score of students' worksheets which is seen from significant value. It means that the significance value ( $P$-Value) for learning factors of $0.000<0.05$, HO is rejected. Thus it can be concluded that there are differences in mathematic students' worksheets of the properties of two dimensional shape between the experimental class and control class after learning is carried out.
\end{abstract}

Keywords: montessori-learning-method, waste-rubber-sponge, active participationstudents

\begin{abstract}
Abstrak: Penelitian ini bertujuan untuk mengetahui pengaruh metode pembelajaran montessori berbasis alat peraga matematika berbahan limbah karet spons terhadap partisipasi aktif siswa kelas 5 SD. Penelitian ini menggunakan metode eksperimen (PretestPosttes Control Group Desaign) dengan menggunakan instrumen berupa lembar observasi, lembar angket, dan lembar hasil belajar siswa. Pengaruh dianalisis menggunakan n-gain dan t-test. Subjek penelitian ini adalah siswa kelas 5 yang ada di Kecamatan Klangenan. Hasil Penelitian ini menunjukkan bahwa pembelajaran montessori berbasis alat peraga matematika berbahan limbah karet spons berpengaruh terhadap partisipasi aktif siswa kelas 5 SD. Hal ini dapat dilihat dari nilai rata-rata hasil postes siswa kelas eksperimen mengalami peningkatan sebesar 28,70. Adanya perbedaan rata-rata skor posttes hasil belajar siswa dilihat dari nilai signifikansi (P-Value) faktor pembelajaran sebesar 0,000< 0,05 H0 ditolak. Dengan demikian dapat disimpulkan bahwa terdapat perbedaan hasil belajar siswa mata pelajaran matematika materi sifat-sifat bangun datar antara kelas eksperimen dan kelas kontrol setelah pembelajaran dilaksanakan.
\end{abstract}

Kata Kunci: metode-pembelajaran-montessori, limbah-karet-spons, partisipasi-aktifsiswa

\section{PENDAHULUAN}

Masalah sampah merupakan masalah besar yang dihadapi oleh setiap Negara termasuk Indonesia. Sampah yang tidak diorganisir dengan baik berdampak negatif terhadap kesehatan masyarakat dan lingkungan. Berbagai penyakit akan muncul akibat sampah. Di dalam UndangUndang Nomor 18 Tahun 2008 tentang Pengelolaan Sampah pasal 3 dijelaskan "Pengelolaan sampah diselenggarakan berdasarkan asas tanggung jawab, asas

'Universitas Muhammadiyah Cirebon, Email: susilawatisaefudin @gmail.com

2Universitas Muhammadiyah Cirebon, Email: widianurjannah87回gmail.com 
berkelanjutan, asas manfaat, asas keadilan, asas kesadaran, asas kebersamaan, asas keselamatan, asas keamanan, dan asas nilai ekonomi". Berdasarkan undang-undang tersebut, sebagai warga Negara Indonesia, kita bertanggung jawab untuk melakukan kegiatan pengelolaan sampah dengan bijak agar dapat menguangi dampak negatif yang ditimbulkan oleh sampah. Salah satu langkah real yang dapat dilakukan untuk mengurangi sampah adalah dengan melakukan reuse terhadap bahan yang sudah tidak lagi bermanfaat.

Kecamatan Klangenan Kabupaten Cirebon Provinsi Jawa Barat merupakan salah satu daerah yang memiliki berbagai industri kreatif yang membuat berbagai jenis mainan yang berbahan limbah karet spons. Berdasarklan hasil wawancara tanggal 03 Maret 2017 dengan pengusaha, limbah karet spons sudah dimanfaatkan untuk membuat berbagai jenis mainan diantaranya adalah pedang-pedangan spons, topeng, reog, parasut mini, kacamata spons, dan aneka mainan lainnya. Berbagai mainan tersebut diproduksi oleh warga sekitar dan didistribusikan ke berbagai toko mainan yang ada di daerah seperti Jakarta, Bandung, Surabaya, Semarang, Medan, dan berbagai daerah sekitar Cirebon. Hasil produksi mainan berbahan dasar limbah karet spons yang sudah dilaksanakan bertahun-tahun sangat membantu perekonomian warga sekitar.

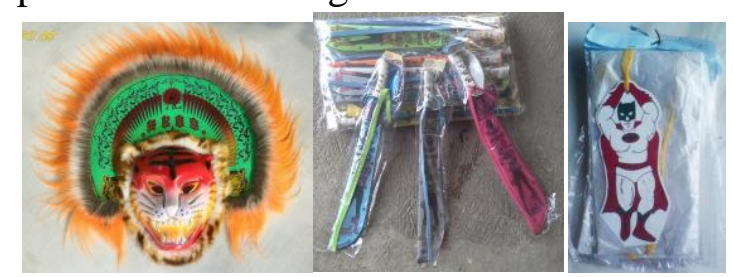

Gambar 1. Mainan Hasil Produksi Hasil Limbah Karet Spons

Disisi lain, pendidikan yang ada di Klangenan masih belum mengoptimalkan media pembelajaran sebagai sarana untuk membangun pemahaman konsep terhadap materi yang dipelajari. Berdasarkan hasil observasi dan wawancara yang telah dilakukan dengan kepala sekolah di Kecamatan Klangenan pada hari Sabtu, tanggal 25 Maret 2017, pada saat menerangkan materi ajar guru-guru jarang sekali menggunakan alat peraga sebagai media pembelajaran di kelas terutama pada mata pelajaran matematika. Mata pelajaran matematika masih dianggap sulit bagi siswa di sana khususnya pada materi sifatsifat bangun datar yang ada di kelas 5 . Siswa bingung membedakan persegi, belah ketupat dan layang-layang. Selain itu, siswa juga kesulitan membedakan berbagai macam segitiga mulai dari segitiga sama kaki, segitiga sama sisi, dan segitiga sikusiku. Sebagian siswa juga masih bingung membedakan rusuk yang sejajar pada sebuah bangun datar. Dengan guru jarang menggunakan alat peraga untuk menyampaikan materi maka berdampak pada partisipasi aktif siswa yang rendah. Hal ini ditunjukkan dengan rendahnya keterlibatan siswa dalam proses pembelajaran di kelas baik dalam bertanya jawab maupun kegiatan diskusi kelompok sehingga pembelajaran cenderung teacher centered. Guru masih terlihat mendominasi kegiatan pembelajaran di kelas.

Berdasarkan masalah yang terjadi dilampangan, maka solusi yang tepat untuk mengatasi masalah tersebut adalah menerapkan metode Montessori. Montessori merupakan salah satu metode pembelajaran yang mengoptimalkan seluruh kemampuan anak melalui stimulasi yang dipersiapkan sehingga semua aspek kognitif, afektif, dan psikomotor siswa berperan dalam proses pembelajaran. Pada filosofi montesori tahapan perkembangan usia 6-12 tahun yaitu di usia sekolah dasar, berada pada masa perkembangan kemandirian mental/moral, sehingga diarahkan pada proses pembelajarannya siswa terlibat aktif sepenuhya, dan mengoptimalkan belajar mandiri untuk memecahkan masalahnya terutama secara berkelompok.

Sebelum menerapkan pembelajaran montessori, guru perlu membuat perencanaan secara rinci dan mempersiapkan lingkungan pembelajaran yang tenang dan teratur agar anak merasa 
nyaman untuk belajar. Montessori (Jones, 2017) mengungkapkan "the child should love everything he learns, for his mental and emotional growths are linked". Montessori menekankan pentingnya memahami kejiwaan seorang anak agar anak merasa nyaman dalam belajar sebagai dasar pendidikan yang tepat. Montessori tidak hanya diimplementasikan bagi anak usia dini tetapi juga untuk anak usia Sekolah Dasar (SD).

Penelitian mengenai implementasi metode montessori di SD telah dilakukan oleh Wahyuningsih (2011) yang mengungkapkan bahwa metode montessori berpengaruh positif terhadap hasil belajar matematika siswa kelas IV SD. Dalam pembelajaran montessori, materi pelajaran menggunakan bahan-bahan konkret untuk melatih anak membaca, menulis, matematika dan pengetahuan sosial. Sejalan dengan itu, Lillard (2012) juga menjelaskan "In fact, recent research found that children attending montessori programs showed increased ability to practice sharing and fairness to solve social problems when compared to children attending conventional programs".

Berdasarkan uraian tersebut, penelitian ini mengimplementasikan dan menganalisis pengaruh metode pembelajaran montessori terhadap partisipasi aktif siswa dalam belajar melalui potensi yang ada di desa tersebut yaitu limbah karet spons. Dengan adanya penelitian ini diharapkan limbah spons yang ada di wilayah sekitar dapat bermanfaat untuk dijadikan alat peraga matematika bagi pendidikan di sekitar Kecamatan Klangenan.

\section{TINJAUAN PUSTAKA}

\section{A. Metode Montessori}

Metode pembelajaran montessori merupakan salah satu metode pembelajaran yang menekankan keaktifan dan kreativitas anak sehingga perkembangan fisik, emosional, intelektual, dan sosial anak dapat tumbuh dan berkembang secara optimal. Konsep pembelajaran montessori ditemukan oleh pakar pendidikan yaitu Dr. Maria Montessori. Montessori is a revolutionary method of observing and supporting the natural development of children. Montessori educational practice helps children develop creativity, problem solving, critical thinking and timemanagement skills, care of the environment and each other, and prepares them to contribute to society and to become fulfilled persons (Montessori, 2017).

Secara normal setiap anak memiliki karakteristik untuk suka mencari tahu, suka ketenangan dan bekerja sendiri, memiliki rasa posesif, ingin melakukan semuanya sendiri, disiplin diri, spontan, serta ceria. Metode montessori mengembangkan berbagai kepribadian anak secara keseluruhan. Metode pembelajaran montessori dibagi menjadi tiga bagian yaitu pendidikan pada aspek motorik, sensorik dan bahasa dengan penekanan melalui pengembangan lima indera. Anak belajar dengan tahapan yang berbeda-beda sesuai dengan kebutuhan dan kecakapankecakapan individunya. Sardiman (2009) menjelaskan ada karakteristik siswa yang perlu diperhatikan, salah satunya adalah yang berkanaan dengan perbedaan kepribadian seperti sikap, perasaan, minat dan lain-lain. Guru harus mampu memberikan kesadaran bahwa perbedaan sikap, perasaan, dan minat adalah hal yang wajar.

Montessori mengembangkan sistem pembelajaran yang berbeda. Montessori mengembangkan metode pedagogi eksperimental dimana guru dan siswa tidak dapat dipisahkan. Guru harus melakukan persiapan untuk menjadi pengamat, sedangkan siswa diberi ruang kemerdekaan untuk beraktivitas secara spontan, sehingga mereka dapat mengekspresikan diri sesuai dengan alam kejiwaan dan kemampuan masing-masing. Hal ini disebabkan masing-masing anak itu unik, model penyeragaman dan penyamaan kegiatan sama sekali tidak memberi tempat bagi berkembangnya alam kejiwaan masingmasing anak. Dengan memberikan 
keleluasaan bagi masing-masing anak untuk beraktivitas, para guru dapat melakukan pengamatan atas perkembangan masing-masing anak secara lebih cermat.

Pengalaman terhadap Lingkungan nyata merupakan aspek penting dalam pembelajaran montessori. Hal ini dijelaskan oleh Montessori (Faryardi, 2007) "Education is a natural process spontaneously carried out by the human individual, and is acquired not by listening to words but by experiences upon the environment. The task of the teacher becomes that of preparing a series of motives of cultural activity, spread over a specially prepared environment, and then refraining from obtrusive interference". Guru tidak perlu campur tangan secara berlebihan dalam proses pembelajaran untuk meningkatkan kreativitas anak.

Montessori (Rittahudin, 2017) menjelaskan perbandingan metode pembelajaran montessori dengan metode pembelajaran tradisional.

Tabel 1. Perbandingan Metode Pembelajaran Montessori dengan Metode Pembelajaran Tradisional

\begin{tabular}{|c|c|}
\hline Montessori & Traditional \\
\hline $\begin{array}{l}\text { Emphasis on more } \\
\text { cognitive learning and } \\
\text { total development }\end{array}$ & $\begin{array}{l}\text { Emphasis on rote } \\
\text { learning and social } \\
\text { development. }\end{array}$ \\
\hline Child-centred learning & $\begin{array}{l}\text { Teacher-centred } \\
\text { learning }\end{array}$ \\
\hline $\begin{array}{l}\text { Child learns by handling } \\
\text { objects and teaching } \\
\text { themselves; } \\
\text { individualised learning } \\
\text { and auto-learning }\end{array}$ & $\begin{array}{l}\text { Teacher directs and } \\
\text { dispenses learning }\end{array}$ \\
\hline $\begin{array}{l}\text { Child completes "cycle of } \\
\text { activity" }\end{array}$ & $\begin{array}{l}\text { Teacher determines } \\
\text { activity cycles by set time }\end{array}$ \\
\hline $\begin{array}{l}\text { Child has freedom to } \\
\text { move and work within } \\
\text { classroom }\end{array}$ & $\begin{array}{l}\text { Child assigned seat and } \\
\text { follows specific class } \\
\text { periods }\end{array}$ \\
\hline $\begin{array}{l}\text { Planned environment } \\
\text { provides selfdiscipline. }\end{array}$ & $\begin{array}{l}\text { Teacher } \\
\text { discipline. }\end{array}$ \\
\hline $\begin{array}{l}\text { Emphasis on concrete } \\
\text { learning. }\end{array}$ & $\begin{array}{l}\text { Emphasis on abstract } \\
\text { learning. }\end{array}$ \\
\hline $\begin{array}{l}\text { Berdasarkan } \\
\text { tersebut dijelaskan } \\
\text { yang dimiliki oleh } \\
\text { dibandingkan dengar }\end{array}$ & $\begin{array}{l}\text { beberapa pendapat } \\
\text { merbagai keunggulan } \\
\text { metode montessori } \\
\text { metode tradisional. }\end{array}$ \\
\hline
\end{tabular}

Dengan demikian, metode montessori layak digunakan di kelas. Selain itu, Dahunsi (2014) juga mengemukakan "Through these developmental needs, the child develops intelligence as well as physical and psychological abilities. The montessori Method of education is designed to take full advantage of the children"s desire to learn and their unique ability to develop their own capabilities. Children need adults to expose them to the possibilities of their lives, but the children must determine their response to all the possibilities". Dengan demikian, melalui metode montessori anak akan mengembangkan kecerdasan serta kemampuan fisik dan psikologis. Namun, anak-anak tetap membutuhkan orang dewasa dalam hal ini guru dan orang tua untuk mengekspos dan membantu mengembangkan berbagai keterampilan yang mereka dimiliki.

\section{B. Alat Peraga Matematika Berbahan Limbah Karet Spons}

Alat peraga merupakan bagian dari media pembelajaran yang bermanfaat untuk memperjelas konsep materi yang dipelajari. Ali (Sundayana, 2014) mengungkapkan alat peraga adalah segala sesuatu yang dapat digunakan untuk menyatakan pesan perangsang pikiran, perasaan, dan perhatian serta kemauan siswa sehingga dapat mendorong proses belajar. Sedangkan Ruseffendi (Sundayana: 2014) mengungkapkan alat peraga matematika adalah alat yang menerangkan atau mewujudkan konsep matematika.

Penggunaan alat peraga sebagai media pembelajaran sangat bermanfaat baik bagi siswa maupun guru. Sadiman (2008, 17) mengemukakan manfaat media pembelajaran secara umum adalah untuk memperjelas penyajian pesan agar tidak terlalu verbalistis; mengatasi keterbatasan ruang, waktu, daya, dan indera; dan mengatasi sikap pasif siswa dalam pelaksanaan pembelajaran. Sikap pasif yang muncul dapat disebabkan tidak ada alat peraga atau media pembelajaran yang menarik. Dengan demikian keberadaan 
media, juga akan meningkatkan motivasi belajar siswa. Palmer (2005) menjelaskan, motivasi merupakan prasyarat untuk belajar. Guru dapat meningkatkan motivasi belajar siswa melalui keberadaan media pembelajaran yang tepat.

Media pembelajaran dalam proses belajar mengajar juga memberikan manfaat yaitu siswa lebih banyak melakukan kegiatan belajar, sebab tidak hanya mendengarkan uraian guru, tetapi juga aktivitas lain seperti mengamati, melakukan, mendemonstrasikan dan lainlain (Sudjana dan Riva'i, 2009). Mengingat banyaknya manfaat yang ada dari penggunaan media pembelajaran, sangat penting bagi guru untuk mendesain alat peraga yang merupakan bagian dari media dalam pembelajaran.

Alat peraga matematika berbahan limbah karet spons merupakan alat peraga yang didesain untuk mata pelajaran matematika dengan menggunakan bahan dasar limbah karet spons. Karet spons yang digunakan dalam penelitian ini adalah limbah yang dihasilkan dari pabrik tikar dan sandal. Limbah ini umumnya dimanfaatkan oleh warga Desa Jemaras Lor untuk membuat berbagai mainan anakanak. Akan tetapi sebagai bentuk inovasi pembelajaran, limbah karet spons ini didesain untuk dijadikan media pembelajaran matematika. Hal ini sejalan dengan kegiatan pengabdian yang dilakukan oleh tim peneliti dengan judul "IbM Alat Peraga Matematika SD dari Pengolahan Sampah Anorganik Karet Sandal di Desa Jemaras Lor Kecamatan Klangenan" yang didanai oleh Simlitabmas Kemenristekdikti pada tahun 2017.

\section{Partisipasi Aktif Siswa}

Partisipasi aktif merupakan hal yang sangat penting dalam proses pembelajaran. Siswa yang aktif menunjukkan keinginan yang besar dalam mengikuti berbagai rangkaian proses pembelajaran. Britha (2011) mengemukakan partisipasi adalah suatu proses yang aktif, yang mengandung arti bahwa orang atau kelompok yang terkait, mengambil inisiatif dan menggunakan kebebasannya untuk melakukan hal itu.

Partisipasi aktif siswa berarti keikutsertaan siswa dalam suatu kegiatan yang ditunjukkan dengan perilaku fisik dan psikisnya. Belajar yang optimal akan terjadi bila siswa berpartisipasi secara tanggung jawab dalam proses belajar. Partisipasi itu dapat terlihat dari beberapa perilaku misalnya mendengarkan, mendiskusikan, membuat sesuatu, menulis laporan, dan sebagainya. Partisipasi siswa dibutuhkan dalam menetapkan tujuan dan dalam kegiatan belajar dan mengajar (Hasibuan \& Moedjiono, 2006).

Beberapa pengertian di atas dapat disimpulkan bahwa partisipasi aktif siswa adalah keterlibatan peserta didik secara fisik maaupun psikis untuk berpikir, berinteraksi, mencoba dan menemukan hal yang baru dalam proses kegiatan pembelajaran sehingga tujuan pembelajaran dapat tercapai. Partisipasi aktif siswa dalam pembelajaran sangat penting untuk menciptakan pembelajaran yang aktif, kreatif dan menyenangkan. Dengan demikian tujuan pembelajaran yang sudah direncanakan dapat tercapai semaksimal mungkin. Tanpa adanya partisipasi dan keaktifan siswa maka proses pembelajaran tidak akan terjadi. Setiap siswa pasti aktif dalam belajar, yang membedakannya adalah tingkat keaktifan siswa tersebut. Tingkat keaktifan siswa dapat dikategorikan mulai dari yang rendah, sedang, tinggi. Agar siswa dapat berpartisipasi aktif selama proses pembelajaran maka diperlukan kreatifitas guru dalam mengajar.

Berbagai faktor yang menyebabkan partisipasi aktif menurut Sudjana (Hayati, 2001) antara lain 1) pengetahuan/kognitif berupa pengetahuan tentang tema, fakta, aturan dan keterampilan; 2) kondisi situasional seperti lingkungan fisik, lingkungan sosial dan faktor-faktor sosial; 3) kebiasaan sosial seperti kebiasaan menetap dan lingkungan; 4) kebutuhan meliputi kebutuhan approach (mendekatkan diri), avoid (menghindari) 
dan kebutuhan individual; 5) sikap meliputi pandangan/perasaan, kesediaan bereaksi, interaksi sosial, minat dan perhatian.

\section{METODOLOGI PENELITIAN}

Penelitian ini dilakukan bertujuan untuk menganalisis pengaruh metode pembelajaran montessori berbasis alat peraga matematika berbahan limbah karet spons terhadap partisipasi aktif siswa Sekolah Dasar. Penelitian yang digunakan adalah penelitian kuantitatif dengan desain penelitian pretest-posttets control group desaign. Pola penelitian ini menurut Sugiyono (2011, hlm. 112) ditunjukkan pada Gambar 2.

\begin{tabular}{|llll|}
\hline Kelas & Pretest & Perlakuan & Posttest \\
\hline $\mathrm{E}$ & $\mathrm{O} 1$ & $\mathrm{X} 1$ & $\mathrm{O} 2$ \\
$\mathrm{~K}$ & $\mathrm{O} 3$ & $\mathrm{X} 2$ & $\mathrm{O} 4$ \\
\hline
\end{tabular}

Gambar 2. Desain penelitian eksperimen PretestPosttes Control Group Sugiyono (2011)

Keterangan:

$\begin{array}{ll}\mathrm{E} & =\text { Kelas Eksperimen } \\ \mathrm{K} & =\text { Kelas Kontrol } \\ \mathrm{O} 1 & =\text { Pretes pada kelompok eksperimen } \\ \mathrm{O} 2 & =\text { Posttes pada kelompok eksperimen } \\ \mathrm{X} 1 & =\text { Perlakuan pada kelompok eksperimen } \\ & \text { menggunakan metode pembelajaran } \\ & \text { montessori berbasis alat peraga matematika } \\ & \text { berbahan limbah karet spons } \\ \mathrm{X} 2 & =\text { Perlakuan pada kelompok kontrol } \\ & \text { menggunakan metode konvenional } \\ \mathrm{O} 3 & =\text { Pretes pada kelompok kontrol } \\ \mathrm{O} 4 & =\text { Posttes pada kelompok kontrol. }\end{array}$

\section{HASIL PENELITIAN DAN PEMBAHASAN}

Penelitian ini dilaksanakan di kelas 5 SDN 3 Klangenan Kecamatan Klangenan Kabupaten Cirebon sebanyak 41 siswa. SDN 3 Klangenan terletak di Jalan Nyi Mas Endang Geulis Desa Klangenan Kecamatan Klangenan Kabupaten Cirebon dengan status Sekolah Standar Nasional (SSN) dan sudah terakreditasi A dengan SK BAN-S/M Nomor: 02.00/691/BAP-SM/X/2011.

Penelitian ini dilakukan bertujuan untuk mengetahui partisipasi aktif siswa SD kelas 5 ketika menggunakan metode pembelajaran montessori berbasis alat peraga matematika berbahan limbah karet spons, mengetahui pengaruh metode pembelajaran montessori berbasis alat peraga matematika berbahan limbah karet spons terhadap partisipasi aktif siswa kelas $5 \mathrm{SD}$, mengetahui perbedaan hasil belajar siswa yang menggunakan metode pembelajaran montessori dengan hasil belajar siswa yang menggunakan cara-cara konvensional. Untuk menjawab semua rumusan masalah maka langkah pertama yang dilakukan adalah melakukan pretes pada kelas eksperimen dan kelas kontrol, langkah yang kedua setelah hasil pretes didapat adalah melakukan proses pembelajaran dengan penerapan metode yang berbeda, kelas eksperimen menggunakan metode montessori dan kelas kontrol menggunakan metode konvensional. Setelah diberikan perlakuan dengan metode yang berbeda maka langkah terakhir adalah melaksanakan postes antara kelas eksperimen dan kelas kontrol.

Adapun hasil pretes pada kelas eksperimen dan kelas kontrol terlihat bahwa kemampuan awal siswa terhadap materi sifat-sifat bangun datar antara kelas eksperimen dan kelas kontrol sama. Tidak ada perbedaan yang sangat signifikan, dimana hal tersebut terlihat dari rata-rata yang diperoleh setiap kelas. Kelas eksperimen mendapatkan rata-rata 47,83 dan rata-rata kelas kontrol adalah 48,06. Sehingga jika kita hitung selisi rata-rata hasil pretes dua kelas tersebut adalah 0,23. Nilai terendah di kelas eksperimen adalah 25 dan kelas kontrol adalah 30. Sedangkan nilai tertinggi dikelas eksperimen adalah 65 sedangkan pada kelas kontrol adalah 60 .

Pengujian hipotesis pretes hasil belajar siswa dengan menggunakan pengujian rerata (uji t) Compare Mean Independent Sampel Test dengan menggunakan prosedur statistik (IBM SPSS Statistics 20 for windows) maka dapat diketahui bahwa nilai signifikansi (PValue) untuk faktor pembelajaran sebesar $0,943 \geq 0,05$ maka $\mathrm{H}_{0}$ diterima. Dengan kata lain, tidak terdapat perbedaan rerata skor pretes hasil belajar matematika siswa antara kelas eksperimen dan kelas kontrol 
berdasarkan faktor pembelajaran. Sedangkan pengambilan keputusan dapat dilakukan dengan cara membandingkan nilai $t_{\text {hitung }}$ dengan $t_{\text {tabel}}$.

Nilai $t_{\text {hitung }}=-0,943$ dan $t_{\text {tabel }}$ dicari dengan tabel distribusi $\mathrm{t}$ pada taraf kepercayaan 95\% $(\alpha=5 \%$, karena uji $\mathrm{t}$ bersifat dua sisi, maka nilai $\alpha / 2=5 \% / 2=$ $0,025)$ dan derajat bebas $(\mathrm{df})=\mathrm{n}-2=41-2$ $=39$, sehingga $\mathrm{t}(0,025 ; 39)=2,022$. $\mathrm{t}_{\text {hitung }}<$ $\pm t_{\text {tabel}}$, maka diputuskan bahwa $\mathrm{H}_{0}$ diterima dan $\mathrm{H}_{1}$ ditolak. Dengan demikian dapat disimpulkan bahwa tidak ada perbedaan hasil belajar siswa antara kelas eksperimen dan kelas kontrol sebelum diberi perlakuan.

Setelah didapat hasil pretes, maka pada pelaksanaan pembelajaran menerapkan metode montessori (kelas eksperimen) siswa dituntut untuk ikut belajar. Belajar bukan saja mengetahui tetapi ikut terlibat dalam aktivitas kelas. Partisipasi siswa harus lebih dominan dibandingkan gurunya. Karena siswa dikatakan belajar dengan kadar tinggi apabila siswa terlibat langsung dalam lingkungan belajarnya. Siswa harus berpartisipasi dalam belajarnya, karena jika siswa berpartisipasi dalam belajarnya maka belajarnya akan optimal. Belajar yang optimal akan terjadi bila siswa berpartisipasi secara tanggung jawab dalam proses belajar. Partisipasi itu dapat terlihat dari beberapa perilaku misalnya mendengarkan, mendiskusikan, membuat sesuatu, menulis laporan, dan sebagainya. Partisipasi siswa dibutuhkan dalam menetapkan tujuan dan dalam kegiatan belajar dan mengajar (Hasibuan \& Moedjiono, 2006).

Upaya yang dilakukan guru untuk meningkatkan partisipasi aktif siswa salah satunya dengan menerapkan metode montesori berbasis alat peraga limbah karet spons. Sebagaimana yang telah dilakukan pada penelitian tanggal 17 - 28 April 2018 di kelas 5 SDN 3 Klangenan Kecamatan Klangenan Kabupaten Cirebon sebanyak 41 siswa. Diketahui hasil partisipasi aktif siswa yang dilihat dari setiap indikatornya meningkat dari setiap pertemuan yaitu pada pertemuan pertama rata-rata aspek proses pembelajaran sebesar 0,693, aspek kerja kelompok sebesar 0,71, aspek motivasi belajar sebesar 0,723, dan aspek kreativitas sebesar 0,536, sedangkan pertemuan kedua rata-rata aspek proses pembelajaran sebesar 0,79, aspek kerja kelompok sebesar 0,71, aspek motivasi belajar sebesar 0,723 , dan aspek kreativitas sebesar 0,726, dan pertemuan ketiga hasil nilai rata-rata aspek proses pembelajaran sebesar 0,783 berarti kenaikan rata-rata dari pertemuan pertama adalah sebesar 0,18 , aspek kerja kelompok sebesar 0,743 berarti kenaikan rata-rata dari pertemuan pertama adalah 0,033 , aspek motivasi belajar sebesar 0,84 berarti kenaikan rata-rata dari pertemuan pertama adalah 0,117, dan aspek kreativitas sebesar 0,90 berarti kenaikan rata-rata dari pertemuan pertama adalah 0,364 . Adapun aspek yang dilihat pada partisipasi aktif siswa tersebut adalah 1). Proses Pembelajaran dengan indikator Memberikan perhatian dan mencatat temuan-temuan penting selama proses pembelajaran berlangsung, Bertanya atau menjawab pertanyaan guru/siswa lain, Berpartisipasi dalam memecahkan masalah, 2) Kerja Kelompok, dengan indikator, Bekerja dalam kelompok, Menyelesaikan tugas dalam kelompok, Melakukan diskusi kelompok, 3) Motivasi Belajar dengan indikator Bersemangat dalam proses pembelajaran, Berani mengemukakan pendapat, Mengerjakan tugas dengan sungguh-sungguh, 4) Kreativitas dengan indikatornya, Memiliki ide untuk memodifikasi media/alat peraga, Tepat dalam membuat media bangun datar, Kreatif dalam menyelesaikan masalah. Untuk lebih jelas melihat kenaikannya maka perhatikan Gambar 3.

Hasil kenaikan partisipasi aktif siswa pada kelas 5 SDN 3 Klangenan Kecamatan Klangenan Kabupaten Cirebon membuktikan bahwa metode montesori berbasis alat peraga limbah karet spons meningkatkan partisipasi aktif yang didominasi oleh kenaikan aspek kreativitas siswa. Hal tersebut sejalan dengan asumsi 


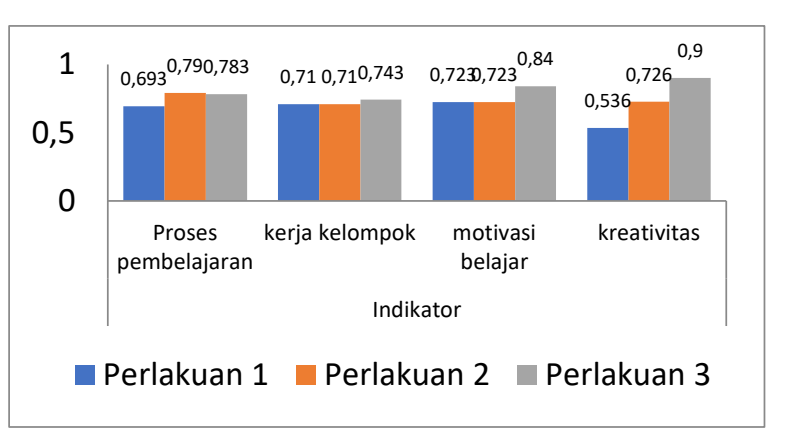

Gambar 3. Hasil Kenaikan Partisipasi Aktif dalam Setiap Pertemuan

Faryardi (2007) bahwa "Education is a natural process spontaneously carried out by the human individual, and is acquired not by listening to words but by experiences upon the environment. The task of the teacher becomes that of preparing a series of motives of cultural activity, spread over a specially prepared environment, and then refraining from obtrusive interference". Guru tidak perlu campur tangan secara berlebihan dalam proses pembelajaran untuk meningkatkan kreativitas anak.

Dengan demikian, lingkungan yang akan membentuk proses belajar siswa yaitu dengan memanfaatkan alat peraga berbasis limbah karet spons. Karena alat peraga juga memiliki peranan penting dalam meningkatkan partisipasi belajar siswa agar kreativitasnya muncul dengan sendirinya.

Berdasarkan data pada gambar 3, maka dapat disimpulkan bahwa metode montessori terbukti dapat berpengaruh terhadap partisipasi aktif siswa sekolah dasar terutama siswa kelas 5 SDN 3 Klangenan. Jika partisipasi aktif siswa meningkat secara optimal diharapkan hasil belajar siswa meningkat. Hal tersebut terbukti dengan penelitian yang telah dilakukan pada hasil postes.

Postes dilaksanakan pada hari Sabtu, tanggal 28 April 2018 di kelas 5 baik kelompok kontrol maupun eksperimen SD Negeri 3 Klangenan Kecamatan Klangenan Kabupaten Cirebon. Soal postes yang diberikan sama dengan soal pretes sebanyak 20 soal. Hasil postes pada nilai rata-rata siswa kelas eksperimen mengalami peningkatan sebesar 28,70. Hal tersebut dilihat dari perbandingan tes kemampuan awal (pretes) siswa dengan posttes, di mana pada saat pretes rata-rata nilai akhir yang diperoleh kelas eksperimen sebesar 48,26 dan perolehan rata-rata nilai akhir posttes kelas eksperimen yaitu sebesar 76,96.

Untuk mengetahui signifikansi perbedaan rerata hasil belajar matematika siswa materi sifat-sifat bangun datar antara kelompok eksperimen dan kelompok kontrol dilakukan uji-t dengan menggunakan uji Compare Mean Independent Sample Test. Adapun hasil perhitungan perbedaan rerata hasil belajar matematik siswa antara kelompok eksperimen dan kelompok kontrol adalah nilai signifikansi (P-Value) untuk faktor

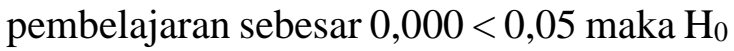
ditolak. Dengan kata lain, terdapat perbedaan rerata skor posttes hasil belajar siswa antara kelas eksperimen dan kelas kontrol berdasarkan faktor pembelajaran. Sedangkan pengambilan keputusan dapat dilakukan dengan cara membandingkan nilai $t_{\text {hitung }}$ dengan $t_{\text {tabel }}$.

Nilai $t_{\text {hitung }}=6,132$ dan $t_{\text {tabel }}$ dicari dengan tabel distribusi $t$ pada taraf kepercayaan $95 \%(\alpha)=5 \%$, karena uji $\mathrm{t}$ bersifat dua sisi, maka nilai $\alpha / 2=5 \% / 2=$ $0,025)$ dan derajat bebas $(\mathrm{df})=\mathrm{n}-2=41-2$ $=39$, sehingga $t(0,025 ; 39)=2,022$. thitung $>$ $\pm \mathrm{t}_{\text {tabel}}$, maka diputuskan bahwa $\mathrm{H}_{0}$ ditolak dan $\mathrm{H}_{1}$ diterima. Dengan demikian dapat disimpulkan bahwa terdapat perbedaan hasil belajar siswa mata pelajaran matematika materi sifat-sifat bangun datar antara kelas eksperimen dan kelas kontrol sesudah diberi perlakuan.

Selain itu dapat dilihat perbedaan rata-rata hasil belajar antara kelas eksperimen dan kelas kontrol pada Gambar 4.

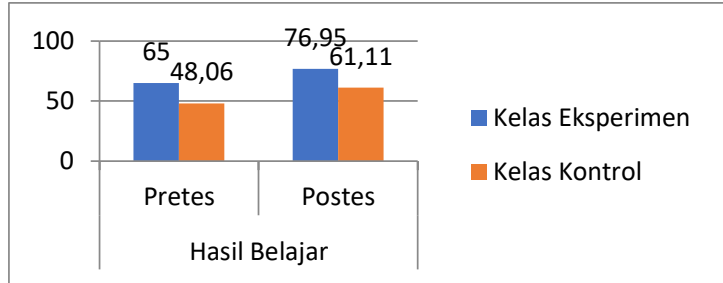

Gambar 4. Perbedaan Rata-rata Kelas Eksperimen dan Kelas Kontrol 
Gambar 4 membuktikan asumsi yang dijelaskan oleh Maria montessori (Sulistyaningsih, 2011) yang mengungkapkan bahwa metode montessori dapat mengarahkan kemandirian diri dalam bekerja dalam kelas atau regulasi diri pada siswa memegang peranan yang sangat penting, siswa harus mampu mengatur dirinya sendiri untuk bekerja seperti menghitung, menulis dan menggali ilmu dan belajar di dalam kelas. Dengan adanya siswa dapat mengatur dirinya sendiri untuk bekerja, dan terdorong untuk menghitung, menulis, dan menggali ilmunya sendiri dengan keaktifan di dalam kelas maka siswa tersebut dikatakan memiliki partisipasi yang aktif dalam pembelajarannya. Kegiatan berhitung, membaca dan menggali ilmunya sendiri dalam belajar lebih mudah lagi dibantu dengan alat peraga. Karena alat peraga atau media pembelajaran memberikan manfaat kepada siswa untuk melakukan aktivitas belajaranya. Sebagaimana yang telah dijelaskan oleh Sudjana dan Riva'i (2009) bahwa media pembelajaran dalam proses belajar mengajar juga memberikan manfaat yaitu siswa lebih banyak melakukan kegiatan belajar, sebab tidak hanya mendengarkan uraian guru, tetapi juga aktivitas lain seperti mengamati, melakukan, mendemonstrasikan dan lainlain.

\section{KESIMPULAN}

Berdasarkan penelitian yang telah dilaksanakan dan hasil analisis data yang telah dilakukan, dapat disimpulkan sebagai berikut.

Partisipasi aktif siswa kelas 5 sekolah dasar terlihat lebih baik pada saat guru menerapkan metode pembelajaran montesori, hal tersebut terlihat dari kenaikan rata-rata nilai partisipasi aktif siswa pada setiap pertemuannya (3 kali pertemuan), dimana pada pertemuan pertama rata-rata nilai partisipai aktifnya sebesar 66,67, pertemuan kedua sebesar 73,91 dan pertemuan ketiga sebesar 81,52. Peningkatan pertemuan pertama dan pertemuan kedua sebesar 7,24. Sedangkan peningkatan pertemuan pertama dan pertemuan ketiga sebesar 7,61.

Pembelajaran montessori berbasis alat peraga matematika berbahan limbah karet spons berpengaruh terhadap partisipasi aktif siswa kelas 5 SD. Hal ini dapat dilihat dari nilai rata-rata hasil postes siswa kelas eksperimen mengalami peningkatan sebesar 28,70. Hal tersebut dilihat dari perbandingan tes kemampuan awal (pretes) siswa dengan posttes, di mana pada saat pretes rata-rata nilai akhir yang diperoleh kelas eksperimen sebesar 48, 26 dan perolehan rata-rata nilai akhir posttes kelas eksperimen yaitu sebesar 76,96.

Ada perbedaan hasil belajar siswa yang menggunakan metode pembelajaran montessori dengan hasil belajar siswa yang menggunakan metode konvensional. Hal ini ditandai dengan adanya perbedaan rerata skor posttes hasil belajar siswa yang dilihat dari hasil yaitu bahwa nilai signifikansi (P-Value) untuk faktor pembelajaran sebesar $0,000<0,05 \mathrm{H}_{0}$ ditolak. Dengan dibuktikannya nilai $t_{\text {hitung }}=$ 6,132 dan $t_{\text {tabel }}$ dicari dengan tabel distribusi $\mathrm{t}$ pada taraf kepercayaan $95 \%(\alpha=5 \%$, karena uji t bersifat dua sisi, maka nilai $\alpha / 2$ $=5 \% / 2=0,025)$ dan derajat bebas $(\mathrm{df})=\mathrm{n}$ $2=41-2=39$, sehingga $\mathrm{t}(0,025 ; 39)=$ 2,022 .

\section{DAFTAR PUSTAKA}

Britha, M. (2011). Metode Penelitian Partisipatoris dan Upaya Pemberdayaan, Jakarta: Yayasan Pustaka Obor Indonesia.

Dahunsi. (2014). Montessori Education in Nigeria. IOSR Journal of Research \& Method in Education (IOSR-JRME) e-ISSN: 2320-7388,p-ISSN: 2320737X Volume 4, Issue 1 Ver. V (Feb. 2014), PP 57-60.

Faryardi, Q. (2007). The montessori paradigm of learning: So what?. Article. Acces on https://eric.ed.gov/?id=ED496081. (Online : 12 Juni 2017) 
Hasibuan dan Moedjiono. (2006). Proses Belajar Mengajar. Bandung: Remaja Rosdakarya.

Hayati, N. (2001). Analisis Faktor-faktor yang menyebabkan Kurangnya Partisipasi Mahasiswa Geografi dalam Kegiatan Berorganisasi. Skripsi. UPI Bandung: tidak diterbitkan.

Jones, S.J. (2017). Technology in the montessori Classroom: Teachers' Beliefs and Technology Use. JoMR Spring Journal of montessori Research 2017. Volume 3, Issue 1. PP. 16-29.

Lillard, A. S. (2012). Preschool children's development in classic montessori, supplemented montessori, and conventional programs. Journal of School Psychology, 50(3), 379-401. doi: 10.1016/j.jsp.2012.01.001

Montessori, M. 2013. Metode montessori: Panduan Wajib untuk Guru dan Orang Tua Didik PAUD, editor: Gerald Lee Gutex, terj. Ahmad Lintang Lazuardi. Yogyakarta: Pustaka Pelajar.

Montessori. (2017). Montessori The International montessori Index. Article. Acces on: www.montessori.edu (Online : 10 Juni 2017)

Palmer, D. (2005). "A Motivational View of Constructivist-informed Teaching". International Journal of Science Education. Volume 27 No. 15. pp. 1853-1881.

Rittahudin, A. (2017). Adaptasi Metode montessori Sebagai Metode Pembelajaran Pendidikan Jasmani di Taman Kanak-kanak dan Sekolah Dasar. Skripsi. Universitas Negeri Yogyakarta. Acces on : http://staffnew.uny.ac.id/upload/132 319841/penelitian/Adaptasi+metode +montessori.pdf (Online : 10 Juni 2017)

Sadiman, A, et. al. (2008). Media Pendidikan. Jakarta: PT. Grafindo Persada.
Sardiman. (2009). Interaksi dan Motivasi Belajar Mengajar. Jakarta: Rajawali Pers.

Sudjana, N \& Ahmad Riva'i. (2009). Media Pengajaran. Bandung: Sinar Baru Algensindo.

Sugiyono. (2011). Metode Penelitian Pendidikan Bandung: Alfabeta.

Sundayana, R. (2014). Media dan Alat Peraga dalam Pembelajaran Matematika. Bandung : Alfabeta.

Undang-Undang Nomor 18 Tahun 2008 tentang Pengelolaan Sampah.

Wahyuningsih, I. (2011). Pengaruh Model Pendidikan montessori Terhadap Hasil Belajar Matematika Siswa. Skripsi. Universitas Islam Negeri Jakarta. Acces on: http://repository.uinjkt.ac.id/dspace/ bitstream/123456789/4715/1/99020INDAH\%20WAHYUNINGSIHFITK.PDF.

\section{Ucapan Terimakasih}

Terlaksananya penelitian ini tidak terlepas dari bantuan dan bimbingan beberapa pihak. Ucapan terima kasih kami sampaikan kepada Direktorat Jenderal Penguatan Riset dan Pengembangan Kementrian Riset, Teknologi dan Pendidikan Tinggi sesuai dengan Surat Perjanjian Pelaksanaan PDP bagi Dosen Perguruan Tinggi Swasta No. 0808/K4/KM/2018 melalui LPPM Universitas Muhammadiyah Cirebon yang telah memberikan dana sehingga penelitian ini dapat berjalan dengan baik dan lancar. 